\title{
Design and experiment evaluation of furrow compaction device with opener for maize
}

\author{
Wenjun Wang ${ }^{1}$, Peisong Diao ${ }^{1 *}$, Honglei Jia ${ }^{2}$, Yulong Chen ${ }^{1}$ \\ (1. School of Agricultural Engineering and Food Science, Shandong University of Technology, Zibo 255000, China; \\ 2. School of Biological and Agricultural Engineering, Jilin University, Changchun 130022, China)
}

\begin{abstract}
The double-disc opener of maize precision seeder is an important component which affects sowing quality. After the double-disc opening operation, there will be many unfavorable phenomena such as a W-shaped bottom with pointed ridge, returning soil to furrow, loose and rough furrow sidewall, and large soil blocks in the furrow bottom. These phenomena often cause the problems of poor sowing depth consistency and seed spacing uniformity. In order to solve the above problems, the furrow compaction device with opener was designed to compact and reshape the original seed furrow, eventually forming a smooth and flat V-shaped seed furrow. Through theoretical calculations and kinematic analysis, the main structural parameters of the device were limited to a small range: the spring stiffness coefficient $k=0.96-4.19 \mathrm{~N} / \mathrm{mm}$ and the angle of the furrow compaction wheel $\varphi=30^{\circ}-60^{\circ}$. In the soil-bin experiment, the rotary combination design was adopted to study the effects of the parameters of the furrow compaction device with opener on the seeds location variation. The regression model of two factors with respect to each indicator was established in the Design-Expert software, revealing the effects of two factors on the indicators. Finally, the optimal structural parameters obtained were: the spring stiffness coefficient $k=4.0 \mathrm{~N} / \mathrm{mm}$, and the angle of furrow compaction wheel $\varphi=42.4^{\circ}$. The field test was carried out to verify the effect of the furrow compaction device with opener on the performance of precision seeder. The results showed that the average values of the sowing depth variable coefficient, the lateral deviation and the seed spacing variable coefficient respectively were $5.77 \%, 5.1 \mathrm{~mm}$ and $9.54 \%$ in the treatment of the furrow compaction device with opener. All indicators were superior to the traditional double-disc opener. This research can provide references for the design of furrow opening device and maize precision seeder.

Keywords: furrow opener, seed furrow, compaction, sowing depth variable coefficient, lateral deviation, seed spacing variable coefficient
\end{abstract}

DOI: $10.25165 /$ j.ijabe.20201302.4941

Citation: Wang W J, Diao P S, Jia H L, Chen Y L. Design and experiment evaluation of furrow compaction device with opener for maize. Int J Agric \& Biol Eng, 2020; 13(2): 123-131.

\section{Introduction}

With the continuous development of modern agriculture technology, the precision seeding has become a main planting way to a variety of crops such as soybean, maize, sugar beets and cotton. The precision seeding could save a lot of seeds, reduce the labor cost of thinning out seedlings in the field and increase crop yields ${ }^{[1-3]}$. In general, precision seeding has high requirements for sowing depth consistency and seed spacing uniformity ${ }^{[4]}$.

The uniform seed depth can promote the growth of crops ${ }^{[5-7]}$. The more uniform plant spacing and row spacing, the higher crop yields ${ }^{[8-14]}$. The reason is that adjacent plants compete for sunshine, water, nutrients and other environmental resources during the growth of crops. When the distribution of environmental resources is unequal, the competition among adjacent plants will be intensified and the weak plants will be at a competitive

\section{Received date: 2019-01-23 Accepted date:2020-01-27}

Biographies: Wenjun Wang, PhD, Lecturer, research interests: soil tillage research and field agricultural machinery, Email: wjwang2016@163.com; Honglei Jia, PhD, Professor, research interests: bionic intelligent agricultural machinery and conservation tillage technology, Email: jiahl@jlu.edu.cn; Yulong Chen, PhD, Lecturer, research interests: precision seeding theory and equipment, Email: cyl06471@ @ sdut.edu.cn.

*Corresponding author: Peisong Diao, PhD, Professor, research interests: seeding and harvesting theory and equipment. School of Agricultural Engineering and Food Science, Shandong University of Technology, Zibo 255000, China. Tel: +86-13864306142, Email: diaopeisong2003@163.com. disadvantage, causing a decline in output. On the contrary, if the plants grow in a uniform environment, the resources will be evenly distributed and utilized without overwhelming competition, which is conducive to the increase of yields ${ }^{[15]}$. Therefore, we should improve the sowing depth consistency and seed spacing uniformity, and try to create a uniform environment for seed as far as possible, so that the plants can use the various resources evenly and increase the yields per unit area.

The improvements of sowing depth consistency and seed spacing uniformity could be realized by the precision seeder. The furrow opener of precision seeder is an important component which affects sowing depth consistency and seed spacing uniformity ${ }^{[16,17]}$. Scholars at home and abroad had conducted a series of in-depth studies on the furrow opening device. Vamerali et al. ${ }^{[18]}$ designed the wide-sweep opener for no-till planter, which could reduce soil volume density and penetration resistance compared with the double-disk opener. Sánchez-Girón et al. ${ }^{[19]}$ analyzed a new furrow opener called the modified Suffolk opener, which had less resistance compared with the chisel-type opener and the non-winged combine opener. Ma et al. ${ }^{[20]}$ studied the bionic ripple opener, whose working performance of reducing adhesion and resistance was about $9 \%$ higher than the traditional furrow opener. $\mathrm{Gu}$ et al. $^{[21]}$ designed the sliding knife furrow opener, which could reduce working resistance significantly. Wang et al. ${ }^{[22]}$ designed the furrow opener and anti-blocking unit for no-till planter, which reduced soil disturbance by $21.5 \%$ and fuel consumption per unit area by $23.65 \%$. Gou et al. ${ }^{[23]}$ designed the 
furrow opener with arc edge, which were applied to no-tillage seeder, could reduce resistance and soil disturbance and had a high stubble breaking efficiency. Most studies had focused on reducing resistance, soil adhesion and disturbance, while little research had been done on the effects of openers on sowing depth consistency and seed spacing uniformity.

Among the common furrow openers, double-disc opener is most widely used, because the double-disc opener has a good working stability at high speed, without stubble blockage, and has small soil adhesion and disturbance ${ }^{[24]}$. However, after double-disc opener working, the seed furrow is loose and has a $\mathrm{W}$-shaped bottom with pointed ridge. At the same time, a part of the soil will return to the furrow to cause the furrow depth inconsistency, resulting in poor sowing depth consistency. The loose and rough furrow causes the seeds to hang on the furrow sidewall instead of falling into the bottom, resulting in lateral deviation of seeds. Due to the large soil blocks in the furrow, seeds entering the furrow will roll until they stabilize at a certain position, which will result in inconsistent seed spacing ${ }^{[25]}$. In addition, the loose soil and large soil blocks at the furrow bottom are not conducive to the seed-soil contact, affecting seed germination and seedling emergence ${ }^{[26,27]}$. At present, some no-till planters have been designed a small wheel for seed furrow compaction after sowing, which can improve the poor seed-soil contact, but the problem of poor sowing depth consistency and seed spacing uniformity are not solved.

In order to solve the above problems, the furrow compaction device with opener were designed to compact and reshape the original seed furrow, optimizing the furrow morphology, and providing a high-quality seed furrow environment for seed sowing.

\section{Design of the furrow compaction device with opener}

\subsection{Structure and composition}

The furrow compaction device with opener was designed on the basis of the double-disc furrow opener. It was composed of shank, limiting pin, double-disc, furrow compaction wheel, support bracket, spring and four-bar linkage (Figure 1). The four-bar linkage was arranged between the shank and support bracket. The limiting pin was installed on the shank to limit the lowest point position of furrow compaction wheel. A tension spring was mounted on the four-bar linkage to provide a certain downward pressure to the furrow compaction wheel. The furrow compaction wheel, which was a rigid wheel with the V-shaped working surface, was fixed on the central shaft and could be rotated around it.

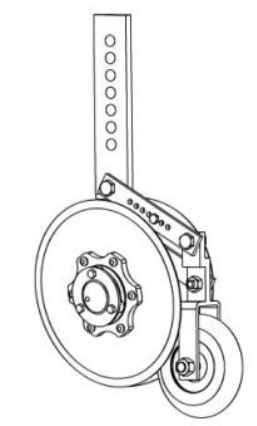

a. Axonometric drawing

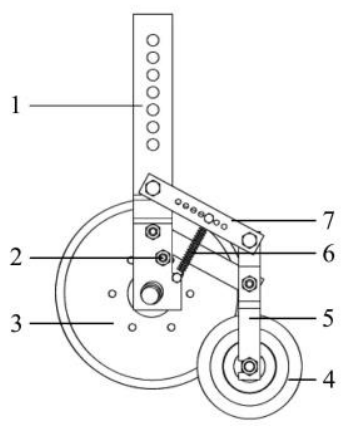

b. Internal structure diagram

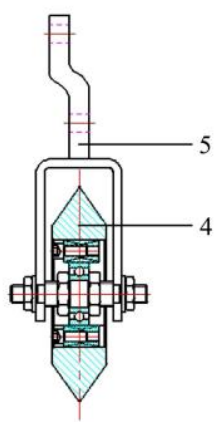

c. Furrow compaction wheel

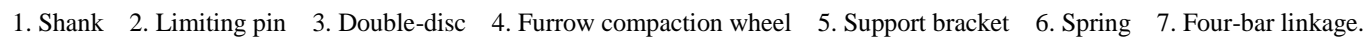

Figure 1 Furrow compaction device with opener

\subsection{Working principle}

During operation, the furrow compaction device with opener moves forward with the seeder frame, and an original furrow was produced by the front double-disc opener. Under the action of the spring and the V-shaped edge, the furrow compaction wheel broke the $\mathrm{W}$-shaped bottom of the original furrow, crushed large soil blocks and pushed excess soils to the furrow sidewalls. In this way, the original furrow was compacted and reshaped, eventually forming a smooth and flat V-shaped seed furrow.

\subsection{Measurement of actual furrow size}

The size of the original seed furrow directly determines the angle parameters of the furrow compaction wheel, so it is necessary to measure the size of the original seed furrow.

The furrow width $b$ after the double-disc operation needs to meet the following formula ${ }^{[28]}$ :

$$
b=d(1-\sin \tau) \sin \frac{\delta}{2}
$$

where, $b$ is the furrow width, $\mathrm{mm}$; $d$ is the disc diameter, $\mathrm{mm} ; \tau$ is the angle between the diameter line across accumulation point and the horizontal line, $\left({ }^{\circ}\right) ; \delta$ is the angle between the two discs, $\left({ }^{\circ}\right)$.

Structure parameters of the double-disc used in this research were: $d=300 \mathrm{~mm}, \tau=23^{\circ}, \delta=14^{\circ}$. The above data were brought to Equation (1), we got the theoretical furrow width of double-disc: $b=22.9 \mathrm{~mm}$.
The furrow angle could be calculated with the following formula:

$$
\varphi=2 \arctan \frac{b}{2 h}
$$

where, $\varphi$ is the furrow angle, $\left({ }^{\circ}\right) ; h$ is the furrow depth, mm.

The sowing depth of maize generally was $30-50 \mathrm{~mm}$, according to Equation (2), we calculated the theoretical furrow angle: $25.8^{\circ}-41.8^{\circ}$. Because the furrow was simplified in the theoretical analysis ${ }^{[28]}$, the obtained theoretical furrow angle was still different from the actual furrow angle. In order to obtain the parameters of furrow compaction wheel, it was necessary to measure the actual furrow angle. Measurement method: after the double-disc operation, we randomly selected 10 measuring points to measure furrow width and furrow depth, respectively, then to calculate the corresponding furrow angle through Equation (2). The purpose of measuring the actual furrow angle was to provide a basis for determining the angle range of furrow compaction wheel. The measurement results of actual furrow size of double-disc are shown in Table 1.

Table 1 showed that the minimum furrow width was $25 \mathrm{~mm}$, so the actual furrow width was greater than the theoretical furrow width $(22.9 \mathrm{~mm})$. The average furrow depth was $34.9 \mathrm{~mm}$, which was less than the average value of theoretical sowing depth $(40 \mathrm{~mm})$. The actual furrow angle range was $31.3^{\circ}-61.2^{\circ}$, which 
was significantly greater than theoretical furrow angle $\left(25.8^{\circ}\right.$ $\left.41.8^{\circ}\right)$. The reason was that after double-disc operation, the soils around seed furrow were loosened and the soil returning into furrow caused shallow furrow depth and large furrow width, resulting in the lager furrow width and the shallower furrow depth. Therefore, the actual furrow angle was greater than the theoretical furrow angle.

Table 1 Measurement results of actual furrow size

\begin{tabular}{cccc} 
Serial No. & Furrow width $b / \mathrm{mm}$ & Furrow depth $h / \mathrm{mm}$ & Furrow angle $\varphi /\left(^{\circ}\right)$ \\
\hline 1 & 25 & 35 & 39.3 \\
2 & 37 & 34 & 57.1 \\
3 & 29 & 38 & 41.8 \\
4 & 31 & 32 & 51.7 \\
5 & 23 & 41 & 31.3 \\
6 & 32 & 29 & 57.8 \\
7 & 33 & 40 & 44.8 \\
8 & 39 & 33 & 61.2 \\
9 & 28 & 32 & 47.3 \\
10 & 25 & 35 & 39.3 \\
Avg. & 30.2 & 34.9 & 47.2 \\
\hline
\end{tabular}

\subsection{Force analysis of furrow compaction wheel}

During the operation process, the furrow compaction wheel worked on the original seed furrow opened by the double-disc opener. The force analysis of the wheel in the seed furrow is shown in Figure 2 $2^{[29]}$.

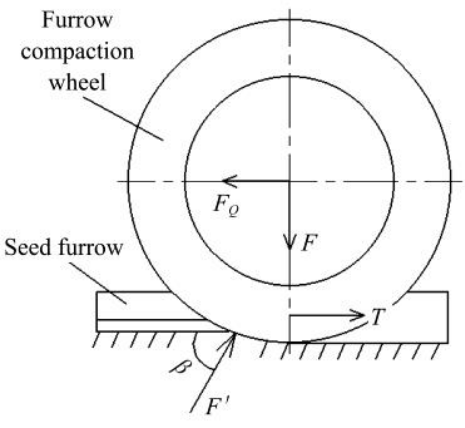

a. Main view drawing

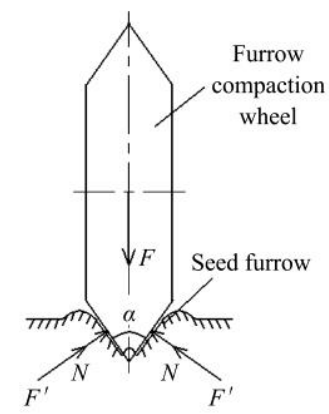

b. Left view drawing
Note: $F$ is the total load acting on furrow compaction wheel, $\mathrm{N} ; F^{\prime}$ is the resistance caused by the $\mathrm{W}$-shaped ridge in the furrow bottom, $\mathrm{N} ; F_{Q}$ is the traction force of furrow compaction wheel, $\mathrm{N} ; \beta$ is the angle between $F^{\prime}$ and horizontal plane, $\left({ }^{\circ}\right) ; \alpha$ is the angle of furrow compaction wheel, $\left({ }^{\circ}\right) ; T$ is the sliding resistance, $\mathrm{N} ; N$ is the normal load acting on working surface of furrow compaction wheel, $\mathrm{N} ; N^{\prime}$ is the normal load caused by water adsorption, $\mathrm{N}$.

Figure 2 Force analysis of the wheel in the seed furrow

In Figure 2, the forces acting on the furrow compaction wheel were decomposed to obtain the following equations:

$$
\begin{gathered}
F=F^{\prime} \sin \beta+2\left(N+N^{\prime}\right) \sin \frac{\alpha}{2} \\
F_{Q}=F^{\prime} \cos \beta+2 T \\
T=\mu N+\mu^{\prime} N^{\prime}
\end{gathered}
$$

where, $F$ is the total load acting on furrow compaction wheel, N; $F^{\prime}$ is the resistance caused by the $\mathrm{W}$-shaped ridge in the furrow bottom, $\mathrm{N} ; F_{Q}$ is the traction force of furrow compaction wheel, $\mathrm{N}$; $\beta$ is the angle between $F^{\prime}$ and horizontal plane, $\left({ }^{\circ}\right) ; \alpha$ is the angle of furrow compaction wheel, $\left(^{\circ}\right) ; T$ is the sliding resistance, $\mathrm{N} ; N$ is the normal load acting on working surface of the wheel, $\mathrm{N} ; N^{\prime}$ is the normal load caused by water adsorption, $\mathrm{N} ; \mu$ and $\mu^{\prime}$ are the friction coefficient and adhesion coefficient between the soil and the working surface of the wheel, respectively.

Equations (3)-(5) were combined to obtain Equation (6):

$$
N=\frac{F-F^{\prime} \sin \beta+2 N^{\prime} \sin \frac{\alpha}{2}}{2 \sin \frac{\alpha}{2}}=\frac{F_{Q}-F^{\prime} \cos \beta-2 \mu^{\prime} N^{\prime}}{2 \mu}
$$

In Equation (6), $F^{\prime} \sin \beta$ was related to the $\mathrm{W}$-shaped ridge, which was formed at the bottom of the original seed furrow by the double-disc opener and whose distribution in the furrow could be regarded as uniform. Therefore, $F^{\prime} \sin \beta$ could be regarded as a constant. There was no significant difference in soil moisture content for the same test site, so $N^{\prime}$ was also a constant. Therefore, the degree of compaction $(N)$ was only related to the total load $(F)$ and the angle of furrow compaction wheel $(\alpha)$. Next, it was necessary to find the optimal $F$ and $\alpha$.

\subsection{Structure parameters of the furrow compaction wheel}

The angle of furrow compaction wheel $\alpha$ was designed based on the actual furrow angle by the double-disc opener. The actual furrow angle was $31.3^{\circ}-61.2^{\circ}$, which had been shown in Table 1, so the angle range of the furrow compaction wheel designed was $30^{\circ}-60^{\circ}$ in this paper.

The width of the furrow compaction wheel was determined according to the furrow depth and the angle of the furrow compaction wheel. The cross-sectional view of the furrow compaction wheel is shown in Figure 3.

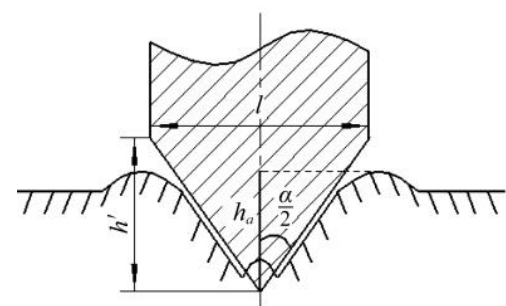

Note: $l$ is the width of furrow compaction wheel, $\mathrm{mm} ; \alpha$ is the angle of furrow compaction wheel, $\left({ }^{\circ}\right) ; h^{\prime}$ is the vertical height of the V-shaped working surface of the wheel, $\mathrm{mm} ; h_{a}$ is the actual furrow depth, $\mathrm{mm}$.

Figure 3 Angle parameters of the furrow compaction wheel

In the operation, it was necessary to ensure that the furrow sidewall completely acted on the V-shaped working surface, so the following formula would be satisfied.

$$
h^{\prime}=\frac{l / 2}{\tan (\alpha / 2)}=\frac{l / 2}{\tan (\varphi / 2)} \geq h_{a}
$$

where, $h^{\prime}$ is the vertical height of the V-shaped working surface of the furrow compaction wheel, $\mathrm{mm} ; l$ is the width of the wheel, $\mathrm{mm}$; $\alpha$ is the angle of the wheel, $\left({ }^{\circ}\right) ; \varphi$ is the actual furrow angle, $\left({ }^{\circ}\right) ; h_{a}$ is the actual furrow depth, $\mathrm{mm}$.

The data in Table $1\left(\varphi=47.2^{\circ}, h_{a}=34.9 \mathrm{~mm}\right)$ were respectively taken into Equation (7), and the width of the furrow compaction wheel was obtained as: $l \geq 30.5 \mathrm{~mm}$. The width of the furrow compaction wheel should not be too large, otherwise it would interfere with the double-disc. So we selected the width of the furrow compaction wheel: $l=32 \mathrm{~mm}$.

The furrow compaction wheel was installed behind the double-disc, so its maximum diameter should be less than the diameter of the double-disc $(d=300 \mathrm{~mm})$. At the same time, the diameter of the furrow compaction wheel should not be too small, otherwise the slipping ratio would be high, and the working performance of compaction and reshaping would be poor. In the design, it was also necessary to consider the installation position of the spring and the support bracket, and the relative position between the furrow compaction wheel and the double-disc. Considering comprehensively, the diameter of the furrow compaction wheel was finally selected to be $D=120 \mathrm{~mm}$. 


\subsection{Spring stiffness coefficient}

The spring stiffness coefficient is related to the load and contact area. The contact between the furrow compaction wheel and the original seed furrow should be analyzed, as shown in Figure 4.

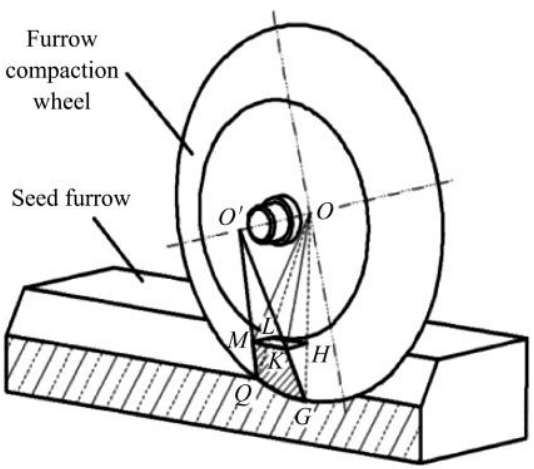

a. Axonometric drawing

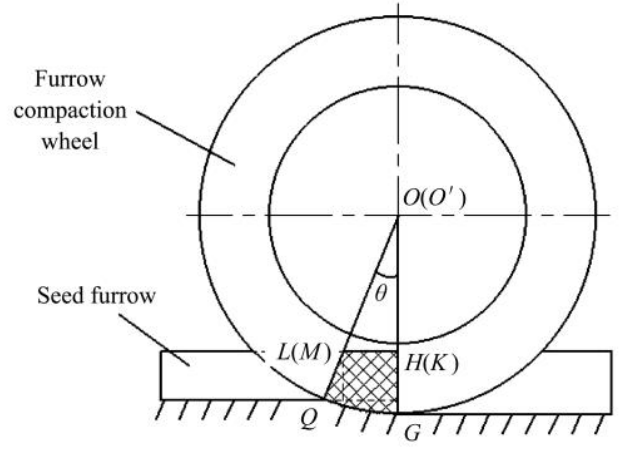

b. Main view drawing

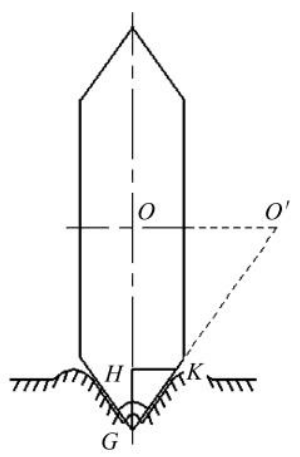

c. Left view drawing

Note: $Q$ and $G$ are the highest point and the lowest point in contact between the V-shaped edge and the furrow bottom, respectively; $O$ is the center point of the wheel; $O^{\prime}$ is the intersection of the conical working surface; $L$ is the intersection of the horizontal plane and line $O Q ; H$ is the intersection of the horizontal plane and line $O G ; M$ is the intersection of the horizontal plane and line $O^{\prime} Q ; K$ is the intersection of the horizontal plane and line $O^{\prime} G$.

Figure 4 Contact analysis of the wheel and the seed furrow

From Figure 4, we got the following equation:

$$
L Q=O Q-O L=\frac{H G-\Delta h}{\cos \theta}
$$

where, $\Delta h$ is the sinkage of the seed furrow, $\mathrm{mm} ; \theta$ is the angle between line $O Q$ and line $O G,\left(^{\circ}\right)$.

Putting $D$ and $h$ into Equation (8) and obtaining:

$$
\frac{D}{2}-\frac{D-2 h}{2 \cos \theta}=\frac{h-\Delta h}{\cos \theta}
$$

Further finishing Equation (9), obtaining:

$$
\cos \theta=\frac{D-2 \Delta h}{D}
$$

In Figure 4, the shaded portion GKMQ is the contact area between the wheel and the furrow, and the area of the shaded portion GKMQ is:

$$
\begin{gathered}
S_{G K M Q}=S_{Q O^{\prime} G}-S_{\triangle K O^{\prime} M} \\
S_{Q O^{\prime} G}=\frac{1}{2} Q G \cdot O^{\prime} G=\frac{D}{4} \cdot \theta \cdot O^{\prime} G \\
S_{\triangle K O^{\prime} M}=\frac{1}{2} O^{\prime} K \cdot O^{\prime} M \cdot \sin \angle K O^{\prime} M \\
O^{\prime} G=\frac{O G}{\cos \frac{\alpha}{2}}=\frac{D}{2 \cos \frac{\alpha}{2}} \\
O^{\prime} K=\frac{O H}{\cos \frac{\alpha}{2}}=\frac{D-2 h}{2 \cos \frac{\alpha}{2}} \\
\frac{O L}{\cos \frac{\alpha}{2}}=\frac{O H}{\cos \theta \cos \frac{\alpha}{2}}=\frac{D-2 h}{2 \cos \theta \cos \frac{\alpha}{2}} \\
\angle K O^{\prime} M=\frac{Q G}{O^{\prime} G}=\frac{\frac{D}{2} \cdot \theta}{\frac{D}{2 \cos \frac{\alpha}{2}}}=\theta \cdot \cos \frac{\alpha}{2}
\end{gathered}
$$

Equations (11)-(17) were combined to obtain the following equation:

$$
S_{G K M Q}=\frac{\theta D^{2}}{8 \cos \frac{\alpha}{2}}-\frac{(D-2 h)^{2} \sin \left(\theta \cos \frac{\alpha}{2}\right)}{8 \cos \theta \cos ^{2} \frac{\alpha}{2}}
$$

The sowing depth was $30-50 \mathrm{~mm}$ for maize and the sinkage was $10 \%$ of the sowing $\operatorname{depth}^{[6]}$, so the maximum value of the sinkage was $\Delta h=5 \mathrm{~mm}$. The data $(D=120 \mathrm{~mm}, h=30-50 \mathrm{~mm}$, $\alpha=30^{\circ}-60^{\circ}, \Delta h=5 \mathrm{~mm}$ ) were taken into Equation (18), then the area of the shaded portion GKMQ was obtained as: $S_{G K M Q}=5.62-8.29$ $\mathrm{cm}^{2}$.

In Equation (6), both $F^{\prime}$ and $N^{\prime}$ are very small, so $F^{\prime}$ and $N^{\prime}$ could be ignored in calculation. Therefore, Equation (6) is simplified to Equation (19).

$$
N=\frac{F}{2 \sin \frac{\alpha}{2}}
$$

So the pressure acting on the seed furrow $(p)$ is:

$$
p=\frac{N}{S_{G K M Q}}=\frac{F}{2 S_{G K M Q} \sin \frac{\alpha}{2}}
$$

The appropriate pressure is generally $30-50 \mathrm{kPa}{ }^{[29]}$. The drought resistance of maize is poor, so a large pressure is required. The pressure selected for this calculation was $p=45 \mathrm{kPa}$. According to Equation (20), we calculated the total load: $F=13.09-37.31 \mathrm{~N}$. The self-weight of the furrow compaction wheel was $0.6 \mathrm{~kg}$. So the spring force in the vertical direction, which was equal to the total load minus the self-weight of the furrow compaction wheel, was $F_{1}=7.21-31.43 \mathrm{~N}$. The force distribution of the furrow compaction wheel is shown in Figure 5.

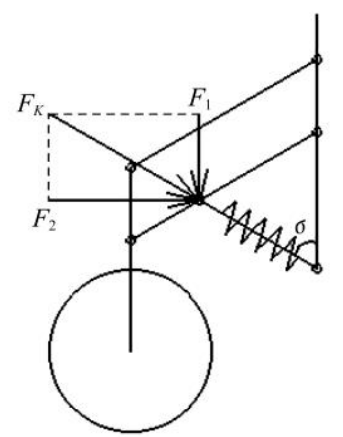

Note: $F_{1}$ is the spring force in the vertical direction, $\mathrm{N} ; F_{2}$ is the spring force in the horizontal direction, $\mathrm{N} ; F_{K}$ is the total spring force, $\mathrm{N} ; \sigma$ is the angle between the spring and the vertical direction, $\left({ }^{\circ}\right)$.

Figure 5 Force analysis of four-bar linkage

By analyzing the spring force in Figure $5, F_{K}$ can be obtained: 


$$
F_{K}=\frac{F_{1}}{\cos \sigma}=k \cdot \Delta x
$$

where, $F_{1}$ is the spring force in the vertical direction, $\mathrm{N} ; F_{2}$ is the spring force in the horizontal direction, $\mathrm{N} ; F_{K}$ is the total spring force, $\mathrm{N} ; \sigma$ is the angle between the spring and the vertical direction, $\left(^{\circ}\right) ; k$ is the spring stiffness coefficient, $\mathrm{N} / \mathrm{mm} ; \Delta x$ is the spring elongation, $\mathrm{mm}$.

During the operation process, the spring was in a stretched state. The data $\left(\sigma=60^{\circ}, \Delta x=15 \mathrm{~mm}\right)$ were taken into Equation (21), then the spring stiffness coefficient was obtained as: $k=0.96-4.19$ $\mathrm{N} / \mathrm{mm}$.

\subsection{Installation position}

The relative position of the furrow compaction device with opener and the seeding port would affect the seeding stability of the whole machine. In order to improve the seeding stability, the installation position of the seeding port should be as close as possible to the furrow compaction wheel. When the four-bar linkage of the device was raised to the horizontal limit position, we should make sure that the seed fell into the seed furrow smoothly without interference from the furrow compaction wheel. According to the size of the double-disc and the furrow compaction wheel, the installation position of the seeding port was that $245 \mathrm{~mm}$ horizontal distance and $90 \mathrm{~mm}$ vertical distance from the center point of the double-disc.

\section{Materials and methods}

\subsection{Experiment preparation}

The experiment was carried out in the indoor soil-bin, College of Biological and Agricultural Engineering, Jilin University, China, from January 18 to 25,2017 . The soil-bin was long of $30 \mathrm{~m}$, width of $2.8 \mathrm{~m}$ and depth of $1.8 \mathrm{~m}$. The soil type was chernozems according to $\mathrm{WRB}^{[30]}$. Before the experiment, the soil physical properties were measured. The soil volume density was $1.02 \mathrm{~g} / \mathrm{cm}^{3}$ at the soil depth of $0-100 \mathrm{~mm}$ and $1.19 \mathrm{~g} / \mathrm{cm}^{3}$ at the soil depth of 100-200 mm. Soil moisture content was measured using a time domain reflectometry TDR (Spectrum Equipment, TDR300 Soil Moisture Meter, USA) with a $12 \mathrm{~cm}$ probe. The average value of soil volume moisture content was $19.0 \%$. Before the start of each test, the soil was crushed by rotary tillage machine and levelled by press roller, then the soil compactness was measured by SC-900 soil compactness meter (Spectrum Equipment, USA) to ensure that the error of the soil compactness is within $10 \%$. The test site is shown in Figure 6.

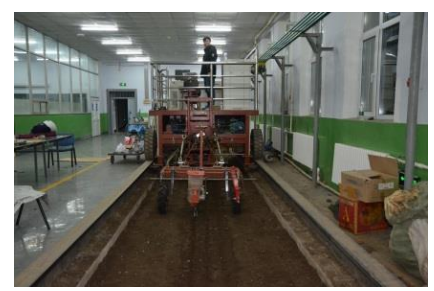

a. Testing vehicle in soil-bin

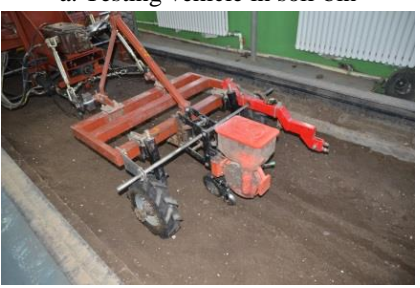

c. Precision drill unit

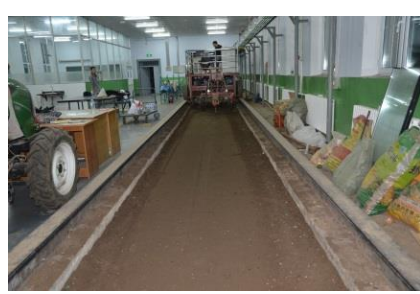

b. Soil treatment before operation

d. Furrow compaction device with opener

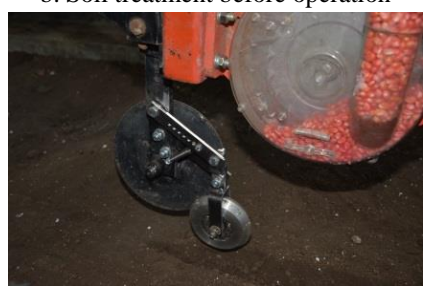

Figure 6 Soil-bin experiment site
The precision drill unit was integrally fixedly installed in the rear suspension bracket of the testing vehicle in soil-bin. In order to maintain the balance of force, a pair of ground wheels were symmetrically installed at the left and right ends of the bracket, and the ground wheel on the right side provides the driving force for seed-metering device. The experiment used a scoop-type seed-metering device with a gearbox, where the hand shank could change the gear ratio to adjust the seed spacing. Before the experiment, the height of the frame was adjusted by the hydraulic system of testing vehicle to ensure that the frame was level with the ground. The stability of the sowing depth was ensured by adjusting the height of ground wheels and the opener. The average working speed of the vehicle was $6.1 \mathrm{~km} / \mathrm{h}$ in the experiment. The first $5 \mathrm{~m}$ was the acceleration zone, the last $5 \mathrm{~m}$ was the deceleration zone, and the middle $20 \mathrm{~m}$ was the data test zone in the soil-bin.

\subsection{Experimental scheme}

In this study, the rotary combination design was adopted to study the effects of the parameters of the furrow compaction device with opener on the seed location variation. Through the previous analysis, the structure parameters of the furrow compaction device with opener were: $k=0.96-4.19 \mathrm{~N} / \mathrm{mm}, \varphi=30^{\circ}-60^{\circ}, l=32 \mathrm{~mm}$, $D=120 \mathrm{~mm}$. The experimental factors included the spring stiffness coefficient and the angle of the furrow compaction wheel. The experimental scheme was designed by Design-Expert software, in which 8 groups were factorial points and 5 groups were zero points. The experimental factors and level coding values are shown in Table 2.

Table 2 Experimental factors and level coding values

\begin{tabular}{ccc}
\hline \multirow{2}{*}{ Levels } & \multicolumn{2}{c}{ Factors } \\
\cline { 2 - 3 } & $\begin{array}{c}\text { Spring stiffness coefficient } \\
x_{1} / \mathrm{N} \cdot \mathrm{mm}^{-1}\end{array}$ & $\begin{array}{c}\text { Angle of furrow compaction wheel } \\
x_{2} /\left(^{\circ}\right)\end{array}$ \\
\hline-1.414 & 1.0 & 30.0 \\
-1 & 1.4 & 34.4 \\
0 & 2.5 & 45.0 \\
1 & 3.6 & 55.6 \\
1.414 & 4.0 & 60.0 \\
\hline
\end{tabular}

\subsection{Measurement method}

(1) Measurement of sowing depth variable coefficient

In each treatment, a seed strip of $2 \mathrm{~m}$ length were randomly selected to measure the depth of each seed, repeating 3 times. The sowing depth variable coefficient would be calculated by Equation (22).

$$
\varepsilon=\sqrt{\frac{\sum\left(h_{i}-\bar{h}\right)^{2}}{n-1}} / \bar{h} \times 100 \%
$$

where, $\varepsilon$ is the sowing depth variable coefficient, $\% ; h_{i}$ is the depth of the $i$-th seed, mm; $\bar{h}$ is the average value of seed depth, mm; $n$ is the number of seeds measured.

(2) Measurement of lateral deviation

In each treatment, a seed strip of $2 \mathrm{~m}$ length were randomly selected, and the left and right deviations of the seeds were measured based on the seed furrow bottom. Each treatment was repeated 3 times and averaged.

(3) Measurement of seed spacing variable coefficient

In each treatment, a seed strip of $2 \mathrm{~m}$ length were randomly selected to measure the seed spacing of adjacent seeds, repeating 3 times. The sowing depth variable coefficient would be calculated by Equation (23).

$$
\omega=\sqrt{\frac{\sum\left(x_{i}-\bar{x}\right)^{2}}{m-1}} / \bar{x} \times 100 \%
$$


where, $\omega$ is the seed spacing variable coefficient, $\% ; x_{i}$ is the seed spacing between the $i$-th seed and the $(i+1)$-th seed, mm; $\bar{x}$ is the average value of seed spacing, $\mathrm{mm} ; m$ is the number of seeds measured.

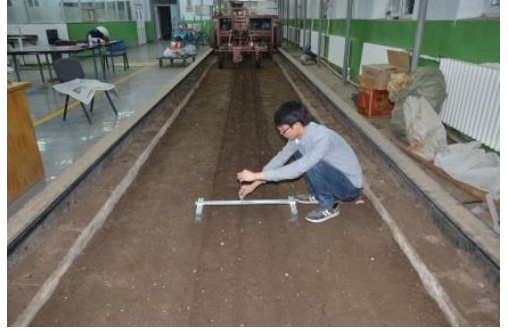

a. Measurement of sowing depth

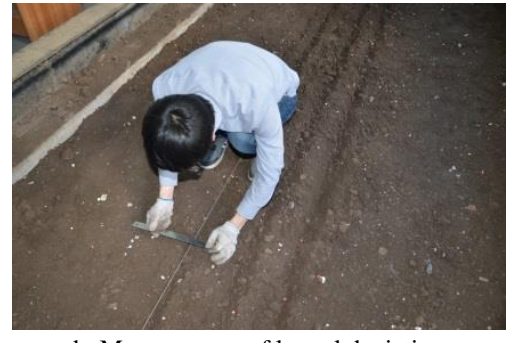

b. Measurement of lateral deviation
The variety of maize seeds used in the experiment was Hongxin 808. The theoretical sowing depth was $5 \mathrm{~cm}$, and the theoretical seed spacing was $26 \mathrm{~cm}$. The measurement processes are shown in Figure 7.

Figure 7 Measurement of indicators

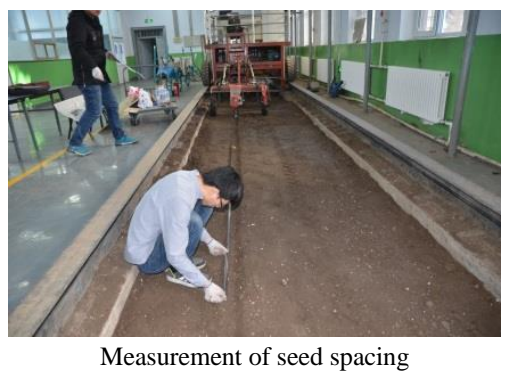

$x_{1} x_{2}$, and $x_{2}^{2}$ were significant, while other factors were not significant. In Table 4, the $p$-value of the lack of fit was 0.1624 , apparently $p>0.05$, that indicated the regression fitting was good. Therefore, Equation (25) can be used to analyze instead of the actual data of the experiment. Compared with the angle of the furrow compaction wheel $x_{2}$, the effect of the spring stiffness coefficient $x_{1}$ on the lateral deviation $y_{2}$ was more significant.

Table 4 and Equation (26) showed that the factors $x_{1}$ and $x_{2}{ }^{2}$ were significant, while other factors were not significant. In Table 4 , the $p$-value of the lack of fit was 0.1957 , apparently $p>0.05$, that indicated the regression fitting was good. Therefore, Equation (26) can be used to analyze instead of the actual data of the experiment.

Table 4 Variance analysis of experimental results

\begin{tabular}{|c|c|c|c|c|c|c|}
\hline $\begin{array}{l}\text { Testing } \\
\text { indicators }\end{array}$ & $\begin{array}{c}\text { Sources of } \\
\text { variation }\end{array}$ & $\begin{array}{l}\text { Sum of } \\
\text { squares }\end{array}$ & Freedom & $\begin{array}{l}\text { Mean } \\
\text { square }\end{array}$ & $F$-value & $p$-value \\
\hline \multirow{9}{*}{$\begin{array}{c}\text { Sowing } \\
\text { depth } \\
\text { variable } \\
\text { coefficient } \\
y_{1} / \%\end{array}$} & Model & 119.44 & 5 & 23.89 & 30.38 & 0.0001 \\
\hline & $x_{1}$ & 11.43 & 1 & 11.43 & 14.53 & 0.0066 \\
\hline & $x_{2}$ & 22.18 & 1 & 22.18 & 28.21 & 0.0011 \\
\hline & $x_{1} x_{2}$ & 5.22 & 1 & 5.22 & 6.64 & 0.0366 \\
\hline & $x_{1}^{2}$ & 3.46 & 1 & 3.46 & 4.40 & 0.0741 \\
\hline & $x_{2}{ }^{2}$ & 71.66 & 1 & 71.66 & 91.14 & 0.0001 \\
\hline & Lack of fit & 3.84 & 3 & 1.28 & 3.06 & 0.1538 \\
\hline & Pure error & 1.67 & 4 & 0.42 & - & - \\
\hline & Sum & 124.94 & 12 & - & - & - \\
\hline \multirow{9}{*}{$\begin{array}{c}\text { Lateral } \\
\text { deviation } \\
y_{2} / \mathrm{mm}\end{array}$} & Model & 53.61 & 5 & 10.72 & 22.53 & 0.0004 \\
\hline & $x_{1}$ & 26.54 & 1 & 26.54 & 55.76 & 0.0001 \\
\hline & $x_{2}$ & 7.10 & 1 & 7.10 & 14.92 & 0.0062 \\
\hline & $x_{1} x_{2}$ & 11.22 & 1 & 11.22 & 23.58 & 0.0018 \\
\hline & $x_{1}^{2}$ & 1.65 & 1 & 1.65 & 3.47 & 0.1046 \\
\hline & $x_{2}^{2}$ & 6.11 & 1 & 6.11 & 12.85 & 0.0089 \\
\hline & Lack of fit & 2.29 & 3 & 0.76 & 2.94 & 0.1624 \\
\hline & Pure error & 1.04 & 4 & 0.26 & - & - \\
\hline & Sum & 56.94 & 12 & - & - & - \\
\hline \multirow{9}{*}{$\begin{array}{c}\text { Seed spacing } \\
\text { variable } \\
\text { coefficient } \\
y_{3} / \%\end{array}$} & Model & 10.94 & 5 & 2.19 & 3.21 & 0.0083 \\
\hline & $x_{1}$ & 5.27 & 1 & 5.27 & 7.73 & 0.0273 \\
\hline & $x_{2}$ & 1.54 & 1 & 1.54 & 2.25 & 0.1769 \\
\hline & $x_{1} x_{2}$ & 0.16 & 1 & 0.16 & 0.24 & 0.6389 \\
\hline & $x_{1}^{2}$ & 0.50 & 1 & 0.50 & 0.73 & 0.4221 \\
\hline & $x_{2}{ }^{2}$ & 3.75 & 1 & 3.75 & 5.50 & 0.0514 \\
\hline & Lack of fit & 3.13 & 3 & 1.04 & 2.53 & 0.1957 \\
\hline & Pure error & 1.65 & 4 & 0.41 & - & - \\
\hline & Sum & 15.71 & 12 & - & - & - \\
\hline
\end{tabular}




\subsection{Corresponding surface analysis of experimental results}

The corresponding surface method in Design-Expert software was used to analyze the effects of the two factors on the three indicators, getting the corresponding surface analysis diagrams, as shown in Figure 8.

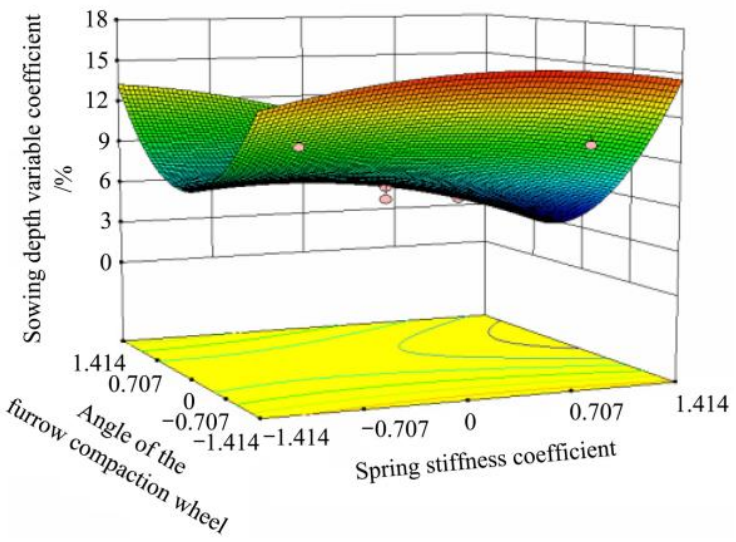

a. Sowing depth variable coefficient

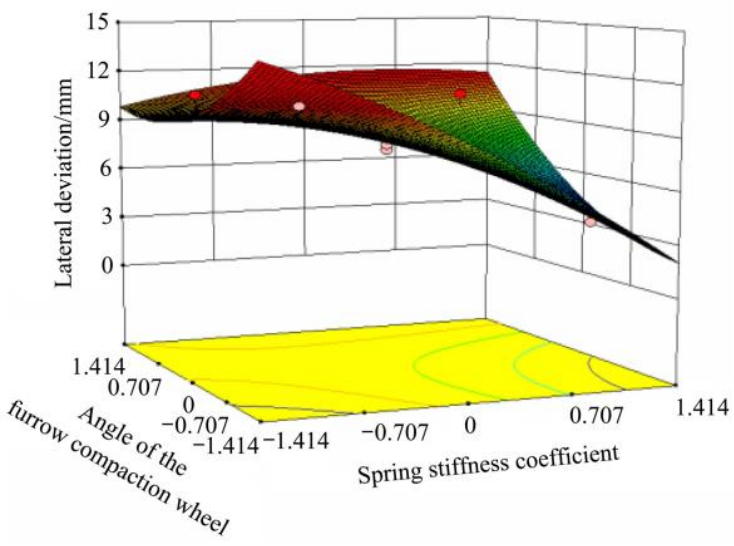

b. Lateral deviation

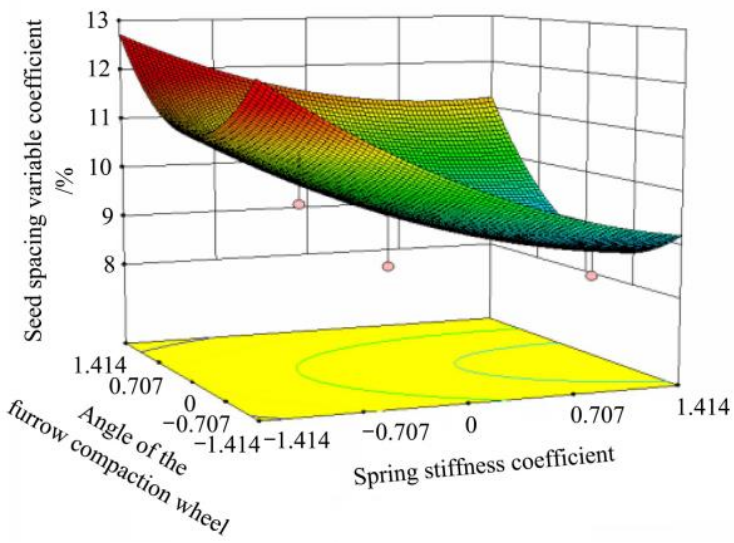

c. Seed spacing variable coefficient

Figure 8 Corresponding surface analysis diagrams

As shown in Figure 8a and Table 4, the effect of the two factors on the sowing depth variable coefficient $y_{1}$ was significant $(p<0.01)$, and there was an interaction between two factors $(p<0.05)$. When the $x_{2}$ was small, the $y_{1}$ increased slightly with the increase of the $x_{1}$; when the $x_{2}$ was large, the $y_{1}$ decreased with the increase of the $x_{1}$. The reason might be that when the $x_{2}$ was small, even if the spring stiffness coefficient increased, the working surface of the furrow compaction wheel could not fully contact and compact the furrow sidewall, resulting in the furrow sidewall not being smooth enough. So some seeds could remain on the furrow sidewall instead of sliding into the furrow bottom, causing a large the sowing depth variable coefficient. When the $x_{2}$ is large, the working surface of the furrow compaction wheel could fully contact and compact the furrow sidewall. The increase of the spring stiffness coefficient could make the furrow sidewall smoother so that the seeds could slide down to the furrow bottom easily, ensuring the stability of the seed depth.

However, the $y_{1}$ tended to decrease first and then increase with the increase of the $x_{2}$. The possible reason was that if the $x_{2}$ was too small, the working surface of the furrow compaction wheel could not fully contact and compact the furrow sidewall, resulting in the furrow sidewall not being smooth enough. So some seeds could remain on the furrow sidewall instead of sliding into the furrow bottom. If the $x_{2}$ was too large, the angle of furrow sidewall was larger than the angle of wall friction, preventing seeds from sliding down into the furrow bottom.

As shown in Figure 8b and Table 4, the effect of the two factors on the lateral deviation $y_{2}$ was significant, and the interaction was also significant $(p<0.01)$. When the $x_{2}$ was small, the $y_{2}$ decreased with the increase of the $x_{1}$; when the $x_{2}$ was large, the $y_{2}$ increased slightly with the increase of the $x_{1}$. That because that when the $x_{2}$ is small, the furrow sidewall was not smooth enough, causing some seeds could remain on the furrow sidewall instead of sliding into the furrow bottom. When the $x_{2}$ is large, the interaction nearly canceled out the performance of the $x_{1}$, so the $y_{2}$ had small change slightly with the increase of the $x_{1}$.

When the $x_{1}$ was small, the $y_{2}$ decreased with the increase of the $x_{2}$ and the downward trend gradually slowed down; when the $x_{1}$ was large, the $y_{2}$ increased with the increase of the $x_{2}$ and the upward trend gradually accelerated. The reason might be that when the $x_{1}$ was small, the larger the $x_{2}$, the smoother the furrow sidewall. The smooth furrow sidewall made it easier for seeds to slide into the furrow bottom. When the $x_{1}$ was large, the increasing $x_{2}$ made the angle of furrow sidewall larger than the angle of wall friction, preventing seeds from sliding down into the furrow bottom, finally resulting in a large lateral deviation.

As shown in Figure 8c and Table 4, the $x_{1}$ had a significant impact the seed spacing variable coefficient $y_{3}(p<0.05)$, while the $x_{2}$ and the interaction did not. The $y_{3}$ decreased with the increase of the $x_{1}$ and the downward trend gradually slowed down. The reason was that the furrow sidewall and bottom were smoother with the increase of the $x_{1}$. The smooth furrow sidewall made it easier for seeds to slide into the furrow bottom.

In Design-Expert software, the optimal parameters of the furrow compaction device with opener are obtained: the spring stiffness coefficient $k=4.0 \mathrm{~N} / \mathrm{mm}$, and the angle of the furrow compaction wheel $\alpha=42.4^{\circ}$. At this time, the model predicted the results as $y_{1}=4.54 \%, y_{2}=4.1 \mathrm{~mm}$, and $y_{3}=8.61 \%$.

\section{Verification test}

In order to verify the performance of the furrow compaction device with opener in the precision seeder, the verification test was conducted on the test field of the Jilin Academy of Agricultural Machinery on April 25-28, 2017. The soil type was chernozems according to WRB, and there was a small amount of stalks covering on the surface. The soil physical properties were measured before the test. The soil volume density was $1.11 \mathrm{~g} / \mathrm{cm}^{3}$ at the soil depth of $0-100 \mathrm{~mm}$ and $1.27 \mathrm{~g} / \mathrm{cm}^{3}$ at the soil depth of $100-200 \mathrm{~mm}$. The average value of soil moisture content was $16.5 \%$. The machine used was 2BYMQF-4 maize precision seeder, whose technical parameters are shown in Table 5. The seeder is equipped with the concave-disc covering device and the 
press roller with a rubber surface, and was powered by John Deere 904 tractor $(66.2 \mathrm{~kW})$. The average working speed of the machine measured was $6.7 \mathrm{~km} / \mathrm{h}$ during the test. The site of field test is shown in Figure 9.

In the test, the furrow compaction device with opener adopted the optimal parameters. The measurement indicators were the sowing depth variable coefficient, the lateral deviation and the seed spacing variable coefficient. The results of field test are shown in Table 6.

Table 5 Main technical parameters of 2BYMQF-4 seeder

\begin{tabular}{lc}
\hline \multicolumn{1}{c}{ Main technical parameters } & Value \\
\hline Overall dimension, $\mathrm{L} \times \mathrm{W} \times \mathrm{H} / \mathrm{mm}$ & $2400 \times 3000 \times 1120$ \\
Working rows & 4 \\
Row spacing $/ \mathrm{mm}$ & $600-700$ \\
Power $/ \mathrm{kW}$ & $62.5-88.2$ \\
Working speed $/ \mathrm{km} \cdot \mathrm{h}^{-1}$ & $4-8$ \\
Rotational speed $/ \mathrm{rad} \cdot \mathrm{s}^{-1}$ & 415 \\
Structural quality $/ \mathrm{kg}$ & 960 \\
\hline
\end{tabular}

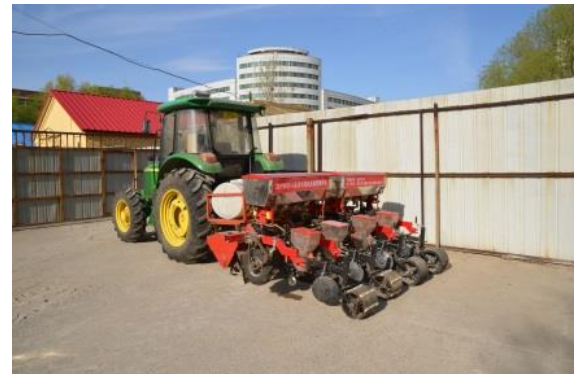

a. 2BYMQF-4 seeder

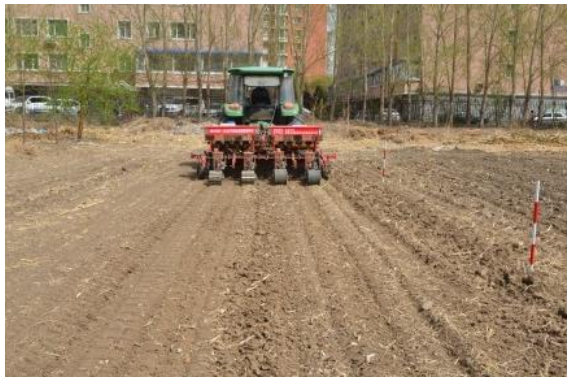

b. Machine operation

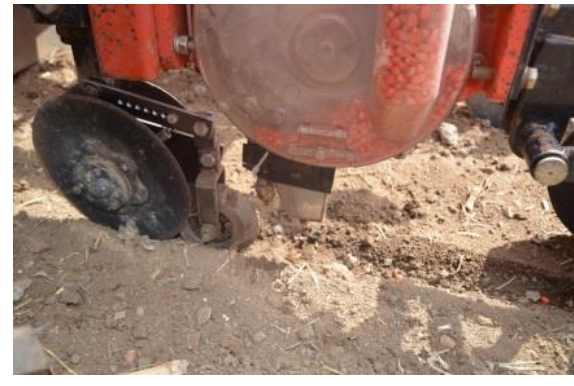

c. Installation position

Figure 9 Site of the field test

Table 6 Results of verification test

\begin{tabular}{|c|c|c|c|c|c|c|}
\hline \multirow{2}{*}{ Serial No. } & \multicolumn{3}{|c|}{ Furrow compaction device with opener } & \multicolumn{3}{|c|}{ Traditional double-disc opener } \\
\hline & $\begin{array}{l}\text { Sowing depth variable } \\
\text { coefficient } / \%\end{array}$ & $\begin{array}{l}\text { Lateral deviation } \\
\qquad / \mathrm{mm}\end{array}$ & $\begin{array}{l}\text { Seed spacing variable } \\
\text { coefficient } / \%\end{array}$ & $\begin{array}{l}\text { Sowing depth variable } \\
\text { coefficient } / \%\end{array}$ & $\begin{array}{l}\text { Lateral deviation } \\
\qquad / \mathrm{mm}\end{array}$ & $\begin{array}{l}\text { Seed spacing variable } \\
\text { coefficient } / \%\end{array}$ \\
\hline 1 & 5.58 & 5.3 & 7.65 & 11.04 & 8.1 & 11.24 \\
\hline 2 & 7.06 & 5.7 & 8.32 & 12.01 & 8.7 & 14.93 \\
\hline 3 & 4.51 & 4.2 & 9.56 & 8.25 & 6.9 & 9.82 \\
\hline 5 & 6.29 & 3.8 & 7.90 & 5.19 & 7.3 & 16.02 \\
\hline 6 & 5.19 & 5.3 & 9.35 & 10.06 & 11.1 & 10.58 \\
\hline 7 & 5.45 & 2.8 & 9.10 & 10.89 & 10.0 & 15.41 \\
\hline 8 & 6.06 & 4.8 & 10.46 & 7.19 & 8.6 & 13.79 \\
\hline 9 & 5.45 & 8.7 & 12.16 & 10.01 & 8.2 & 9.00 \\
\hline 10 & 6.54 & 3.9 & 10.20 & 11.62 & 9.3 & 14.82 \\
\hline Avg. & 5.77 & 5.1 & 9.54 & 9.82 & 8.9 & 12.97 \\
\hline
\end{tabular}

The results of field test showed that the average values of the sowing depth variable coefficient, the lateral deviation and the seed spacing variable coefficient respectively were $5.77 \%, 5.1 \mathrm{~mm}$ and $9.54 \%$ in the treatment of the furrow compaction device with opener. The values of three indicators were slightly larger than the theoretical values of the regression model established in the soil-bin test. The possible reason was that the morphology of the seed furrow was disturbed by the complex field conditions, such as a small amount of stalks covering on the surface, some gravels mingled in the soil, and the low soil moisture content.

The average values of the sowing depth variable coefficient, the lateral deviation and the seed spacing variable coefficient respectively were $5.77 \%, 5.1 \mathrm{~mm}$ and $9.54 \%$ in the treatment of the traditional double-disc opener. The test results showed that three indicators in the treatment of the furrow compaction device with opener were superior to the traditional double-disc opener.

In order to further evaluate the effect of the furrow compaction device with opener on the performance of the whole machine, the qualification rate of seed spacing was measured and calculated. The results showed that the qualification rate of seed spacing of the furrow compaction device with opener and the traditional double-disc opener were $94.6 \%$ and $88.1 \%$, respectively, which both met the requirements of the national standards.

\section{Conclusions}

(1) The furrow compaction device with opener was designed to compact and reshape the original seed furrow, forming a smooth and flat $\mathrm{V}$-shaped seed furrow, effectively improving the sowing depth consistency and seed spacing uniformity. Through theoretical calculation and kinematics analysis, the main structural parameters of the device were limited to a small range: the spring stiffness coefficient $k=0.96-4.19 \mathrm{~N} / \mathrm{mm}$ and the angle of the furrow compaction wheel $\varphi=30^{\circ}-60^{\circ}$.

(2) In the soil-bin experiment, the rotary combination design was adopted to study the effect of the parameters of the furrow compaction device with opener on the seed location variation. The regression model was established in the Design-Expert software, revealing the effect of the two factors on the three indicators. Finally, the optimal structural parameters were: the spring stiffness coefficient $k=4.0 \mathrm{~N} / \mathrm{mm}$, and the furrow compaction wheel angle $\varphi=42.4^{\circ}$.

(3) The field test was carried out to verify the performance of the furrow compaction device with opener in the precision seeder. The results showed that the average values of the sowing depth variable coefficient, the lateral deviation and the seed spacing variable coefficient respectively were $5.77 \%, 5.1 \mathrm{~mm}$ and $9.54 \%$ in 
the treatment of the furrow compaction device with opener. All indicators were superior to the traditional double-disc opener. Moreover, the qualification rate of seed spacing were $94.6 \%$ and $88.1 \%$ respectively, which both met the requirements of national standards.

\section{Acknowledgements}

The financial support for this study came from three projects: the National Key Research and Development Program of China (Grant No. 2017YFD0700703), the Development Program of Science and Technology of Jilin Province of China (Grant No. 20170312005ZX), and the National Natural Science Foundation of China (Grant No. 51905318). At last, we highly appreciate Dr. Shanghua $\mathrm{Wu}$ who are the researchers of Jilin Academy of Agricultural Machinery for providing the experimental site and guiding the field experiment.

\section{[References]}

[1] Yang L, Yan B X, Zhang D X, Zhang T L, Wang Y X, Cui T. Research progress on precision planting technology of maize. Transactions of the CSAM, 2016; 47(11): 38-48. (in Chinese)

[2] Doerge T, Hall T, Gardner D. New research confirms benefits of improved plant spacing in corn. Crop insights, 2002; 12(2): 1-5.

[3] Chen J, Li J H, Li Y M, Gong Z Q. Analysis of Suction Height and Seed-adding Device for Suction-vibration Precision Seeder. Transactions of the CSAM, 2013; 44(S1): 67-71. (in Chinese)

[4] Li X P, Ma F L, Gao L X. Dropping impact experiment on corn seeds. Transactions of the CSAE, 2009; 25(1): 113-116. (in Chinese)

[5] Molatudi R L, Mariga I K. The effect of maize seed size and depth of planting on seedling emergence and seedling vigor. Journal of Applied Sciences Research, 2009; 5(12): 2234-2237.

[6] Ozmerzi A, Karayel D, Topakci M. Effect of sowing depth on precision seeder uniformity. Biosystems Engineering, 2002; 82(2): 227-230.

[7] Huang D Y, Zhu L T, Jia H L, Yu T T. Automatic control system of seeding depth based on piezoelectric film for no-till planter. Transactions of the CSAM, 2015; 46(4): 1-8. (in Chinese)

[8] Wiggans R G. The influence of space and arrangement on the production of soybean plants. Agronomy Journal, 1939; 31(4): 314-321.

[9] Moore S H. Uniformity of plant spacing effect on soybean population parameters. Crop Science, 1991; 31(4): 1049-1051.

[10] Krall J M, Esechie H A, Raney R J, Clark S. Influence of within-row variability in plant spacing on corn grain yield. Agronomy Journal, 1977; 69(5): 797-799.

[11] Joseph G L, Mike R. Corn response to within row plant spacing variation. Agronomy Journal, 2004; 96(5): 1464-1468.

[12] Kocher M F, Coleman J M, Smith J A, Kachman S D. Corn seed spacing uniformity as affected by seed tube condition. Applied Engineering in Agriculture, 2011; 27(2): 177-183.

[13] Yazgi A, Degirmencioglu A. Optimisation of the seed spacing uniformity performance of a vacuum-type precision seeder using response surface methodology. Biosystems engineering, 2007; 97(3): 347-356.

[14] Zhao Z, Li Y M, Chen J, Xu L Z. Numerical analysis and laboratory testing of seed spacing uniformity performance for vacuum-cylinder precision seeder. Biosystems Engineering, 2010; 106(4): 344-351.

[15] Zhang X, Wang Z S, Zhao H J, Ru G L, Sun X X, Zhao X L, Zhang X. A summary of plant-to-plant competition in crop yield trials. Tianjin Agricultural Sciences, 2010; 16(3): 90-93. (in Chinese)

[16] Tessier S, Saxton K E, Papendick R I, Hyde G M. Zero-tillage furrow opener effects on seed environment and wheat emergence. Soil and Tillage Research, 1991; 21(3-4): 347-360.

[17] Erbach D C, Wilkins D E, Lovely W G. Relationships Between Furrow Opener, Corn Plant Spacing, and Yield 1. Agronomy Journal, 1972; 64(5) 702-704.

[18] Vamerali T, Bertocco M, Sartori L. Effects of a new wide-sweep opener for no-till planter on seed zone properties and root establishment in maize (Zea mays, L.): A comparison with double-disk opener. Soil and Tillage Research, 2006; 89(2): 196-209.

[19] Sánchez-Girón V, Ramırez J J, Litago J J, Hernanz J L. Effect of soil compaction and water content on the resulting forces acting on three seed drill furrow openers. Soil and Tillage Research, 2005; 81(1): 25-37.

[20] Ma Y H, Ma S S, Jia H L, Liu Y C, Peng J, Gao Z H. Measurement and analysis on reducing adhesion and resistance of bionic ripple opener. Transactions of the CSAE, 2014; 30(5): 36-41. (in Chinese)

[21] Gu Y Q, Jia H L, Guo H, Zhao W G, Zhao X T. Design and experiment of sliding knife furrow opener. Transactions of the CSAM, 2013; 44(2): 38-42. (in Chinese)

[22] Wang Q J, He J, Li H W, Lu C Y, Su Y B. Design and experiment on furrowing and anti-blocking unit for no-till planter. Transactions of the CSAE, 2012; 28(1): 27-31. (in Chinese)

[23] Gou W, Ma R C, Yang W Y, Fan G Q, Lei X L, Hui K, Yang H Z. Design of opener on no-till wheat seeder. Transactions of the CSAE, 2012; 28(S1): 21-25. (in Chinese)

[24] Zhao J H, Yang X J, Zhou J P, Liu L J, Yang H. Analysis the current situation about furrow opener and its performance test device. Journal of Agricultural Mechanization Research, 2014; 36(1): 238-241. (in Chinese)

[25] Iqbal M, Marley S J, Erbach D C, Kaspar T C. An evaluation of seed furrow smearing. Transactions of the ASAE, 1998; 41(5): 1243.

[26] Jia H L, Zheng J X, Yuan H F, Guo M Z, Wang W J, Yu L L. Design and experiment of a double-v-shaped furrow opener of soybean seeder. Journal of Jilin University (Engineering and Technology Edition), 2017; (1) 323-331. (in Chinese)

[27] Jia H L, Zheng J X, Yuan H F, Guo M Z, Wang W J, Jiang X M. Design and experiment of profiling sliding-knife opener. Transactions of the CSAE, 2017; 33(4): 16-24. (in Chinese)

[28] Yao Z L, Gao H W, Wang X Y, Li H W. Effect of three furrow openers for no-till wheat seeder on crop growth performance. Transactions of the CSAE, 2007; 23(7): 117-121. (in Chinese)

[29] Jia H L, Wang W J, Zhuang J, Luo X F, Yao P F, Li Y. Design and experiment of profiling elastic press roller. Transactions of the CSAM, 2015; 46(6): 28-34. (in Chinese)

[30] Gong Z T, Chen Z C, Zhang G L. World reference base for soil resources (WRB): establishment and development. Soils, 2003; 35(4): 271-278. 